\title{
Sarcomatoid Carcinoma with Osseous Differentiation in the Bladder
}

\author{
Luis F. Arenas, Dercilio A. Fontes, Emilio M. Pereira, Flavio L. Hering
}

Portuguese Beneficent Hospital, Sao Paulo, SP, Brazil

\begin{abstract}
Introduction: Bladder sarcomatoid carcinoma is a very rare variant of transitional cell carcinoma. With disputed nomenclature, the tumor has been described previously under a variety of names such as sarcomatoid carcinoma, pseudosarcoma, malignant mixed mesodermal/Müllerian tumor, metaplastic carcinoma and spindle cell carcinoma. This malignancy represents $0.3 \%$ of all bladder tumors and has an aggressive behavior yielding a poor prognosis despite radio and chemotherapy. Case Report: An 81 y/o man presented with a transitional cell carcinoma and underwent a transurethral resection. Adjuvant onco-BCG was introduced. After 9 months of follow-up, a local tumoral recurrence occurred and a new transurethral resection revealed sarcomatoid carcinoma with osseous elements. A radical cystoprostatectomy was then carried out.
\end{abstract}

Key words: bladder neoplasms; transitional cell; BCG vaccine; carcinosarcoma; cystectomy Int Braz J Urol. 2006; 32: 563-5

\section{INTRODUCTION}

Sarcomatoid carcinoma (SC) of the urinary bladder is a variant of Transitional Cell Carcinoma (TCC). SC contains sarcoma-like areas with either spindle or pleomorphic cells. The aggressive behavior of the tumor precludes radical therapy whenever possible, since adjuvant therapy seems to have little effect on the tumor natural history. We report on a case of SC with osseous element, with emphasis on the peculiar clinical and histopathological features.

\section{CASE REPORT}

A 81-year-old man presented with irritative lower urinary tract symptoms. Ultrasound showed thickening of the right posterior bladder wall and a cystoscopy revealed a $3 \mathrm{~cm}$ hyperemic verrucous lesion. Transurethral resection of the lesion was performed and the histopathology revealed a TCC with no muscle invasion. The patient presented hematuria 9 months later and a cystoscopy revealed a $5 \mathrm{~cm}$ tumor in the right bladder wall. Onco BCG (Bacilli Calmette-Guérin), $40 \mathrm{mg}$ once a week for 8 weeks was successfully administered. Seven months later, the patient presented hematuria again. A cystoscopy with biopsy revealed a high grade, muscular invasive TCC with a pattern of sarcomatoid carcinoma with osseous differentiation. Radiotherapy had no effect. Radical cystoprostatectomy was performed with an uneventful follow-up. The surgical specimen revealed a tumoral mass of $9 \mathrm{~cm}$ in diameter with a histopathologic pattern of a high grade TCC (Figure-1) with osteosarcomatous heterologous elements (Figure-2). Adjacent fat tissue was tumor free. A month later, a 


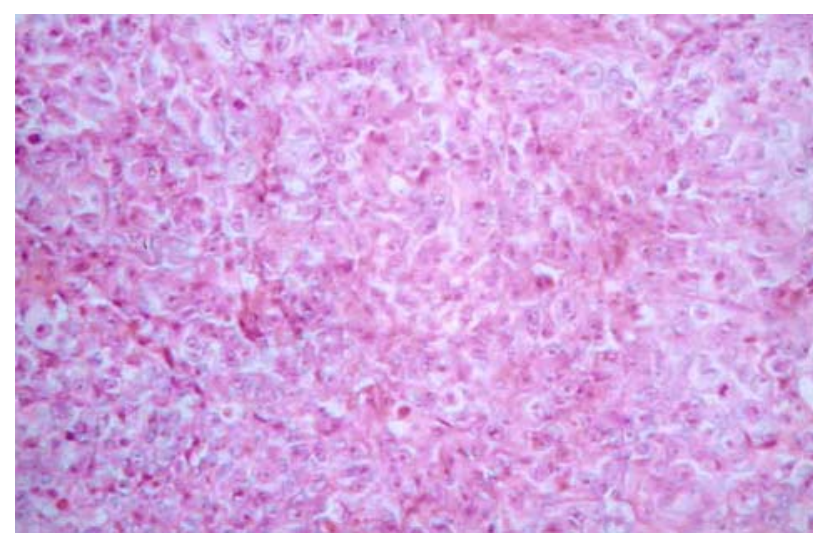

Figure 1 - Area of high grade urothelial carcinoma of the urinary bladder (HE, X100).

chest X-ray showed multiple pulmonary nodules consistent with metastases and died 2 months after this diagnosis.

\section{DISCUSSION}

Bladder SC is an uncommon tumor. Fewer than 70 cases of primary heterologous carcinosarcoma of the urinary bladder have been reported. Terminology for this tumor has been varied and some authors define $\mathrm{SC}$ as a tumor that contains further mesenchymal elements in addition to spindle cells.

The presence of spindle cell in a urinary bladder TCC warrants the designation of SC and some authors define carcinosarcoma as an admixture of malignant epithelial and malignant soft tissue elements (1). Grossly these tumors tend to be polypoid and ulcerated. At histology, the cellular arrangement may have various patterns such as that of the fascicular or storiform appearance of a leiomyosacoma or malignant fibrous histiocytoma. For a carcinosarcoma, the stem cell from which the epithelial and mesenchymal components are derived is expected to be more immature than the epithelial stem cell from which different components of sarcomatoid carcinoma originate, since in the latter, immunohistochemical or ultrastructural epithelial characteristics are still detectable. However, comparative genomic hybridization strongly suggests a monoclonal origin for all those tumors (2).

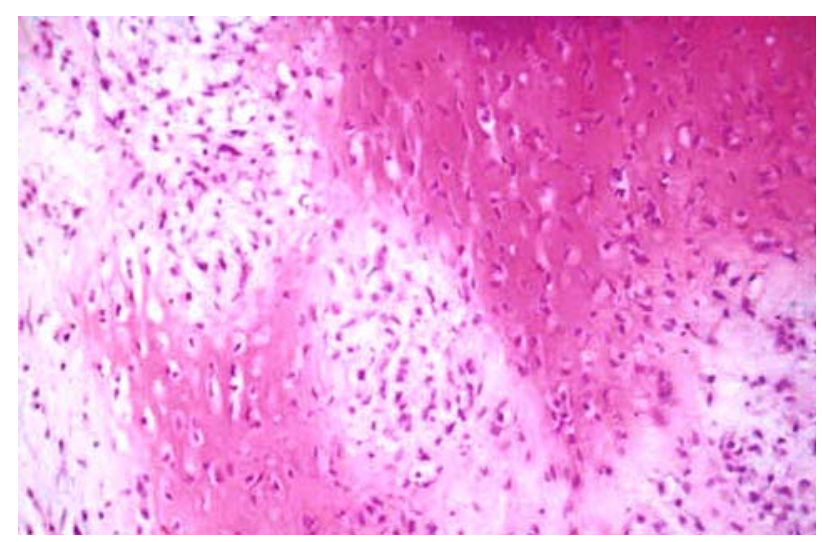

Figure 2 - Bone differentiation beside areas of poorly differentiated carcinoma (HE, X100).

The tumor has poor prognosis. Records of Mayo Clinic (1936-1995) preclude that the tumors occur predominantly in male smokers, mean age of 72 years (1). Signs and symptoms include cloth hematuria, dysuria, pollakiuria and urinary infection. At initial diagnosis, almost all patients have advanced stage disease with muscularis mucosa involvement. Most patients died of local disease or of lymph node, lung, pleura, brain, liver and bone metastases.

Radical cystoprostatectomy should always be considered to bladder SC. Froehner et al. (3) reported a case of a metastatic $\mathrm{SC}$ remission of the bladder with cisplatin and gemcitabine, although, in the literature, adjuvant radiotherapy or adjuvant chemotherapy are apparently of no effect.

\section{CONFLICT OF INTEREST}

None declared.

\section{REFERENCES}

1. Lopez-Beltran A, Pacelli A, Rothenberg HJ, Wollan PC, Zincke H, Blute ML, et al.: Carcinosarcoma and sarcomatoid carcinoma of the bladder: clinicopathological study of 41 cases. J Urol. 1998; 159: 1497503.

2. Torenbeek R, Hermsen MA, Meijer GA, Baak JP, Meijer CJ: Analysis by comparative genomic hybrid- 
ization of epithelial and spindle cell components in sarcomatoid carcinoma and carcinosarcoma: histogenetic aspects. J Pathol. 1999; 189: 338-43.
3. Froehner M, Gaertner HJ, Manseck A, Wirth MP: Durable complete remission of metastatic sarcomatoid carcinoma of the bladder with cisplatin and gemcitabine in an 80-year-old man. Urology. 2001; 58: 799.

Accepted after revision:

February 10, 2006

\section{Correspondence address:}

Dr. Luis Fernando Arenas

Urologisches Klinikum

Heinrich-Heine Univesität Düsseldorf

Steinbrinkstrasse, 96a

46145, Oberhausen, Germany

E-mail: luis64@ig.com.br 